\title{
Enhanced Growth of Okra (Abelmoschus esculentus) in Soil Amended with Biochar and Fulvic acid
}

\author{
Qiang Liu ${ }^{1,2}$, Kudakwashe Meki ${ }^{1,2}$, Xiaohan $\mathrm{Ma}^{1,2, *}$ \\ ${ }^{1}$ Institute of Coastal Environmental Pollution Control, Key Laboratory of Marine Environment and Ecology, Ministry of \\ Education, Ocean University of China, Qingdao, 266100, China \\ ${ }^{2}$ College of Environmental Science and Engineering, Ocean University of China, Qingdao 266100, China
}

\begin{abstract}
Biochar (BC) and fulvic acid (FA) have raised wide interest because of their multiple benefits in soil improvement. However, the difference between individual and co-application of biochar and fulvic acid on okra growth in salt-affected soils is unknown. In this study, a woody waste derived BC and a commercial FA were applied into a coastal salt-affected soil collected from the Yellow River Delta to investigate their effects on a commercial crop, okra (Abelmoschus esculentus) seedling growth following the individual and combined applications using a pot experiment. The results showed the individual and co-application of BC and FA increased the plant height, stem diameter and fresh biomass by $9.4-11.5 \%, 10.3-41.7 \%$ and $31.6-$ $40.0 \%$, respectively, and individual application posed a better performance than co-application. Moreover, $\mathrm{BC}$ and FA individual and combined application could effectively improve the root growth of okra, whereas the individual application posed a greater effect. These findings would provide theoretical basis and technical support for developing green technologies for remediating degraded coastal wetland soils, thus ensuring sustainable agricultural development.
\end{abstract}

\section{Introduction}

Degradation of coastal salt-affected soil weakens the sustainability of coastal primary productivity, thus threatens the availability and use of cultivated land and food security [1-2]. Therefore, it is urgent to restore these degraded coastal wetland ecosystems using eco-friendly technologies. Biochar is a highly aromatized C-rich material, produced under oxygen-free or oxygen-limited conditions at low-temperature pyrolysis $\left(<700{ }^{\circ} \mathrm{C}\right)$ [3]. Biochar has the advantage of strong stability, developed pore structure, large specific surface area, rich surface functional groups, and other excellent characteristics [4], widely used in soil carbon sequestration, soil restoration, water pollution restoration and other fields [5-6]. However, biochar could also have negative effects on plant growth, which were mainly attributed to the different types of soils, plants, and biochar, as well as the interactions between them [7]. Moreover, biochar generally increased soil $\mathrm{pH}$ due to its inherent alkaline feature, which cannot meet the basic requirements of salt - damaged soil for plant growth. Fulvic acid is a type of organic matter produced and accumulated through a series of processes of microbial decomposition and transformation from plant litter or their residue, which contains a large number of organic acids, phenols, aliphatic fatty acid tails, aromatic hydrocarbons and so on

[8]. In recent years, the benefits of fulvic acid had been widely reported and confirmed, such as promoting plant growth through mediating tissue and physiological changes in roots and shoots, and alleviating abiotic stress due to inducing changes of primary and secondary metabolism in plant [9]. Moreover, fulvic acid was believed to play a stimulant role in protecting plants against salt stress [10]. Accordingly, fulvic acid could benefit plant growth in coastal salt-affected cropland. The combined application of fulvic acid and biochar may be an effective method to alleviate plant salt stress and promote plant growth. However, the effect of the coapplication biochar and fulvic acid on okra (Abelmoschus esculentus) growth in coastal salt-affected soil has limited available information, and whether application alone or in combination has a better effect on plant growth is also unknow.

In this study, a pot experiment was conducted to investigate the response of okra (Abelmoschus esculentus) growth following the individual or co-application of biochar and fulvic acid. The findings of this study could provide effective basis for functional biochar to improve plant growth and coastal salt-affected soil amended.

\section{Materials and methods}

\subsection{Soil and amendments}

The soil was collected from the Dongying Halophytes Garden $\left(118.67^{\circ} \mathrm{N}, 37.42^{\circ} \mathrm{E}\right)$, located in the Yellow River

* Corresponding author: maxiaohan@stu.ouc.edu.cn 
Delta, China. The surface soil 0-20 $\mathrm{cm}$ above the ground was collected by the multi-point mixed sampling method. Then, the soil samples were brought back to the laboratory for natural air drying, and obvious sundries such as stones and residual roots were removed. After thoroughly mixing, the soil was passed through a 2-mm sieve for use. The $\mathrm{pH}$, electrical conductivity (EC), and Exchangeable sodium (Ex-Na) values of soil were $8.88,1.17 \mathrm{dS} \mathrm{m}^{-1}$ and $1.14 \mathrm{cmol} \mathrm{kg}^{-1}$, respectively, and soil was classified as saltaffected soil. Biochar was produced from woody waste collected by a local furniture factory in a self-designed carbonization furnace at $450^{\circ} \mathrm{C}$ for 6 hours using slowly pyrolyzed, then air-dried and ground through a $2 \mathrm{~mm}$ sieve. The $\mathrm{pH}$ and EC of biochar were 9.43 and $0.25 \mathrm{dS} \mathrm{m}^{-1}$, respectively [11]. Fulvic acid was purchased from Shanghai Aladdin Biochemical Technology Co., Ltd. in 2017.

\subsection{Pot experiment}

The prepared biochar was incorporated into the selected soil at rates of $3 \%(\mathrm{w} / \mathrm{w})$, referred to as BC. Fulvic acid was formulated to $50 \mathrm{mg} / \mathrm{L}$, and then applied to saltaffected at $20 \%(\mathrm{v} / \mathrm{w})$, referred to as FA. In addition, another portion of the soil was treated with the same rates of biochar and fulvic acid, which is recorded as BFA. The salt-affected soil without added was used as a blank control and was recorded as CK. The plastic pot $(50 \mathrm{~cm}$ in length, $30 \mathrm{~cm}$ in width, $20 \mathrm{~cm}$ in depth) used in this study were filled with $15 \mathrm{~kg}$ the soil or biochar-soil mixture, and were cultivated for one week at $60 \sim 70 \%$ of maximum water holding capacity (WHC) in the greenhouse before seed sowing. A typical cash crop, okra (Abelmoschus esculentus), was used in this pot experiment. Okra (Abelmoschus esculentus) is an annual herb of the Malvaceae family, widely planted in tropical and temperate regions, with rich nutrients and high economic value. At the same time, okra has wide adaptability to the soil, and has a great tolerance to soil with higher salinity. The seeds of okra used in the experiment were purchased from Fuxin Nong Seed Shop in Qingdao, Shandong Province. Ten seeds were sowed in each pot, and the best one was selected for further experiment. During the cultivation, all pots were maintained at $65 \%$ of the maximum WHC of each treated soil using distilled water. After 20 days of cultivation, the shoots and roots of the okra were separately harvested. The plant height and stem diameter of okra were measured using a vernier caliper (500-173, Mitutoyo, Japan) and a ruler, respectively. Afterwards, the shoots and roots were rinsed in Milli-Q water for removing the soil and other debris, and the fresh weight of the shoots and roots were weighed by an electronic balance (TP-214, Denver Instrument, USA). The root morphological parameters, including length, tips, volume, and surface area, were scanned and analyzed using Epson Scanning (Expression 10000XL, Epson, Japan) and WinRhizo Pro. 2005.

\subsection{Statistical analysis}

All results are expressed as averages $(n=4)$. The error bars that appear in the results indicate the standard deviation. Product and Service Solution Software 20.0 (SPSS 20.0) using one-way analysis of variance (ANOVA) and Duncan multi-range test $(\mathrm{P}=0.05)$ were used to analyze the significant differences between treatments.

\section{Results and discussion}

\subsection{Effects of biochar and fulvic acid on shoot height and stem diameter of okra seedling}

The shoot height of okra in the soil treated with individual and co-application of biochar and fulvic acid were shown in Figure 1 (a). Compared with CK, the individual FA and $\mathrm{BC}$ application increased the plant height of okra by $9.4 \%$ and $11.5 \%$, respectively, whereas the co-application decreased the plant height of okra by $8.3 \%$. Still, no significant difference $(\mathrm{P}>0.05)$ was observed in all treatments, indicating that individual and co-application of BC and FA had no effect on shoot height of okra.
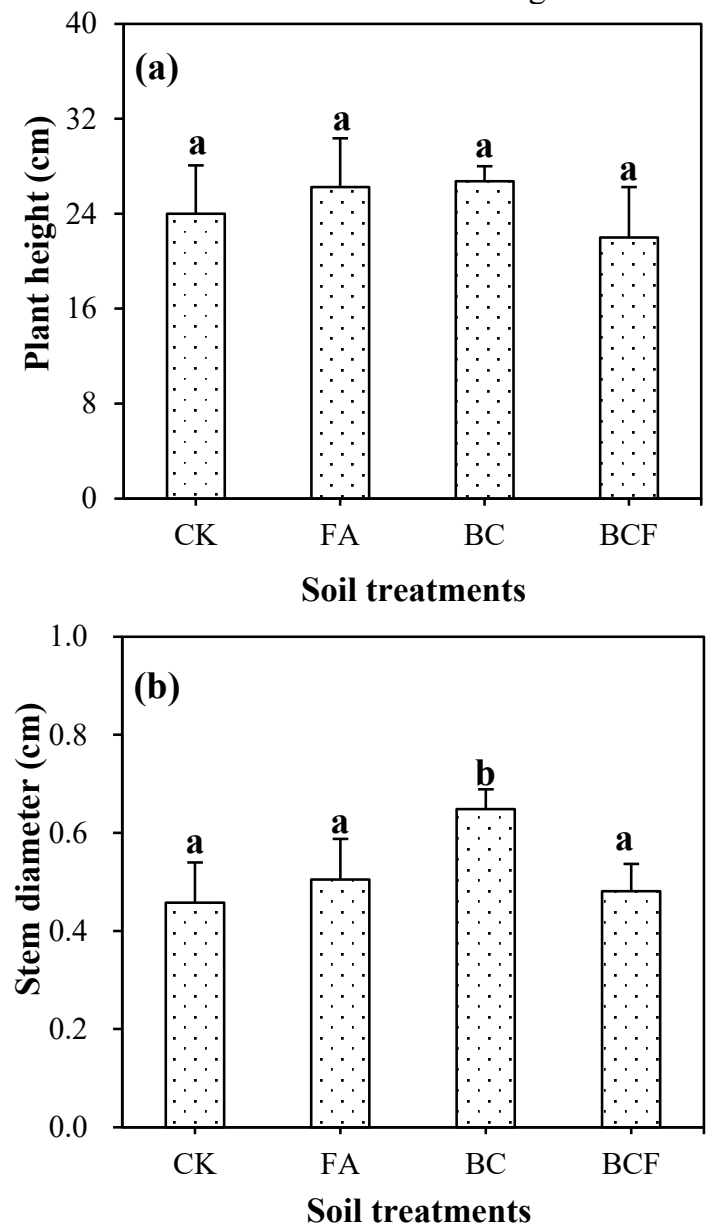

Figure 1. Effect of adding biochar and fulvic acid on shoot height (a) and stem diameter (b) of okra seedling. The bars represent the standard deviation of the means $(n=4)$. The lowercase letters on the bars indicate significance analysis, using Duncan's test $(\mathrm{P}<0.05$; SPSS 20.0.)

The stem diameter of okra in the soil treated with individual and co-application of $\mathrm{BC}$ and fulvic acid shown by Figure 1 (b). Compared with the CK, FA, BC and BCF 
increased the stem diameter of okra by $10.3 \%, 41.7 \%$, and $5.1 \%$, respectively, whereas the significant influence was observed only in $\mathrm{BC}$, indicating that individual and coapplication of biochar and fulvic acid could have a positive influence on stem diameter of okra, but the individual application had a better performance.

\subsection{Effects of biochar and fulvic acid on fresh biomass of okra seedling}

The fresh biomass of okra in the soil treated with individual and co-application of biochar and fulvic acid were shown in Figure 2. For the total biomass of the plant, the individual FA and BC application increased the fresh biomass of okra by $31.6 \%$ and $40.0 \%$ compared with CK, respectively, whereas the co-application decreased the plant height of okra by $14.2 \%$. Compared with the individual application, the co-application significant decreased the fresh biomass of okra by $34.8 \%$ and $38.7 \%$, respectively, indicating that individual application could have greater positive effect than co-application. Similar phenomena were also found on the roots and shoots of okra. For example, compared with $\mathrm{CK}$, the individual application of FA and BC increased the shoots and roots biomass by $31.4 \%, 40.1 \%$ and $35.1 \%, 40.0 \%$, respectively. Still, BCF decreased the fresh plant biomass by $14.3 \%$ and $12.7 \%$. Compared with the individual application, the co-application significantly decreased the shoot and root fresh biomass of okra by $34.7 \%, 38.8 \%$, and $35.4 \%$, $37.7 \%$, respectively.

In summary, the individual application of BC and PA could effectively increase okra biomass attributed to soil properties and enhanced microbial activity by the application of BC and FA [12-13]. Moreover, the individual application showed a more significant positive effect than co-application, which probably due to the biochar could absorb the active components of fulvic acid (e.g., phenols and organic acids) because of its rich surface functional groups and developed pore structure, and reduced positive effect of co-application of biochar and fulvic acid on plant growth [14].

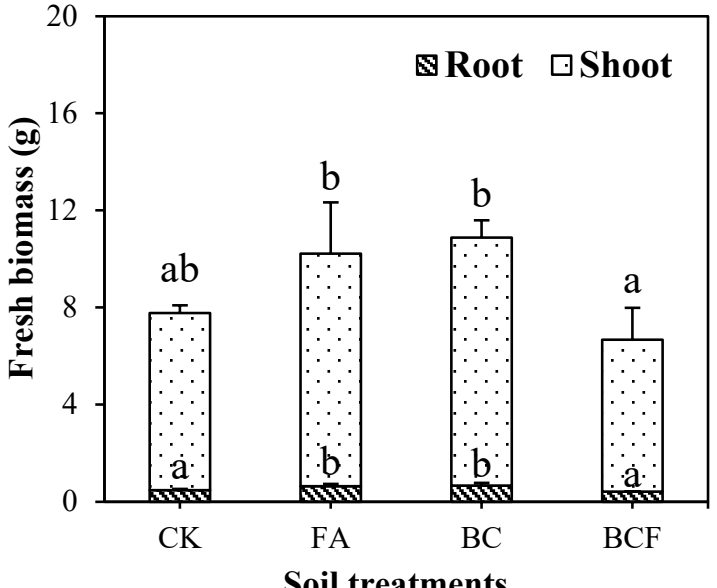

Figure 2. Effect of adding biochar and fulvic acid on plant fresh biomass of okra seedling. The bars represent the standard deviation of the means $(n=4)$. The lowercase letters on the bars indicate significance analysis, using Duncan's test ( $\mathrm{P}$ $<0.05$; SPSS 20.0.)

\subsection{Effects of biochar and fulvic acid on root morphology of okra}

The root length and surface of okra in the soil treated with individual and co-application of biochar and fulvic acid shown by Figure 3 (a)(b). Compared with CK, the FA, BC, and $\mathrm{BCF}$ increased the root length and surface of okra by $69.4 \%$ and $152 \%, 65.5 \%$ and $87.0 \% 31.5 \%$ and $52.2 \%$, respectively, whereas the individual application showed the better performance.
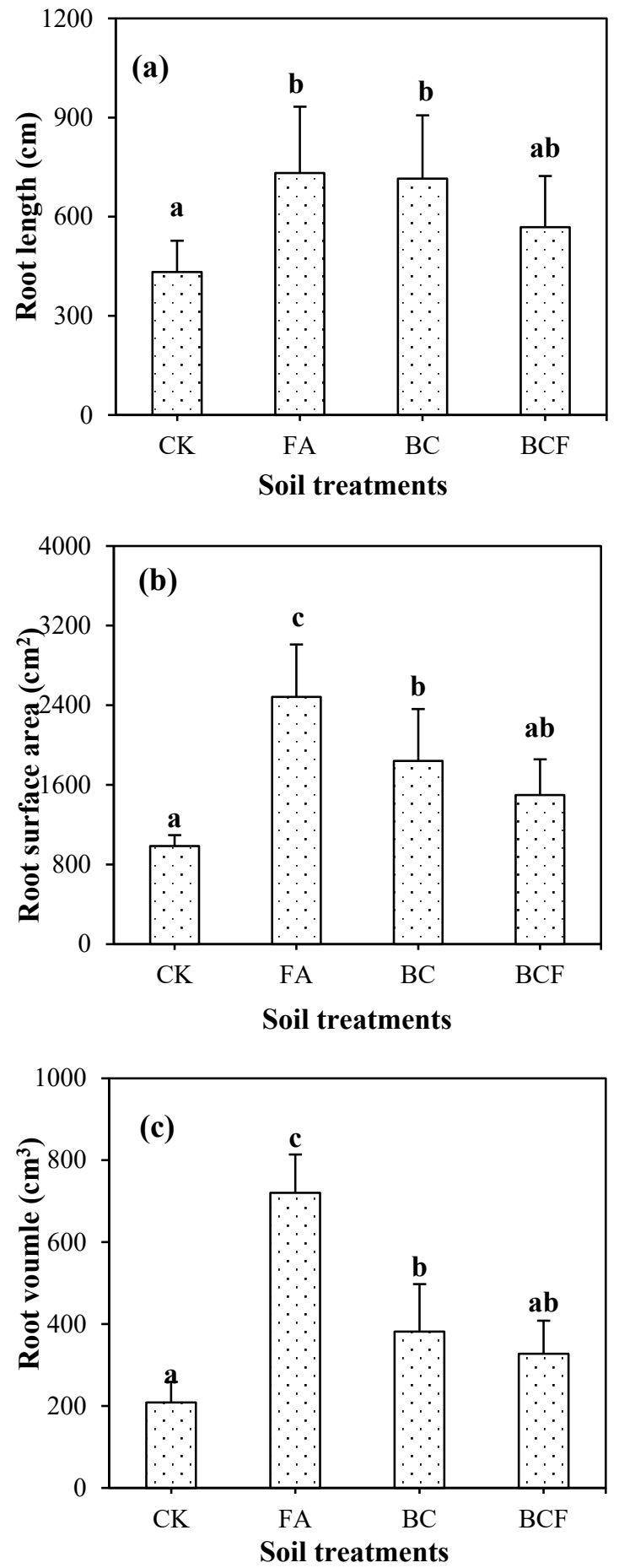


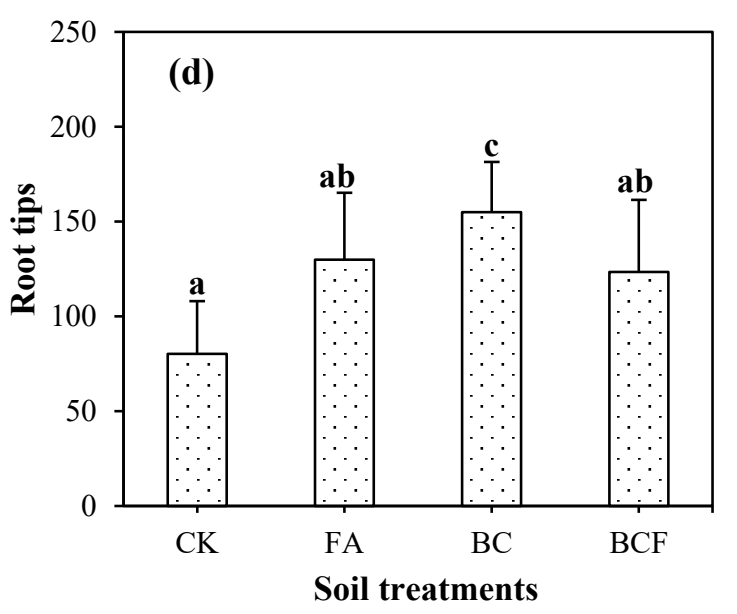

Figure 3. Effect of adding biochar and fulvic acid on root length (a), surface (b), volume (c) and tips (d) of okra seedling. The bars represent the standard deviation of the means $(n=4)$. The lowercase letters on the bars indicate significance analysis, using Duncan's test $(\mathrm{P}<0.05$; SPSS 20.0.)

The root volume and okra tips in the soil treated with the individual, and co-application of biochar and fulvic acid were shown in Figure 3 (c)(d). For root volume, the FA and BC significantly increased the root volume of okra by $246 \%$ and $83.2 \%$ relative to $\mathrm{CK}$, while the $\mathrm{BC}$ increased the root volume of okra by $57.2 \%$. For root tips, the $\mathrm{BC}$ significantly increased the root volume of okra by $93.8 \%$ relative to $\mathrm{CK}$. Moreover, there was an increasing tendency of $\mathrm{BC}$ and $\mathrm{BCF}$ to root tips compared with $\mathrm{CK}$, but no significant difference was found. In summary, the individual and co-application of $\mathrm{BC}$ and $\mathrm{FA}$ could significantly enhance the root growth of okra, while the individual application posed a better performance.

\section{Conclusions}

Our results revealed that individual application of $\mathrm{BC}$ and FA could effectively enhance the okra growth, probably due to soil properties and microbial activity enhanced by application of BC and FA. Moreover, the co-application of $\mathrm{BC}$ and FA could promote the plant growth such as stem diameter and root growth, but showed a lower promotion effect than individual application. The mechanisms for that may be attributed to the adsorption of biochar reduced positive effect of co-application of BC and FA. Therefore, our results demonstrated that coapplication of biochar and fulvic acid could be a practical and promising strategy to elevating plant growth of the degraded coastal soil, but more efforts are still needed to improve their efficacies.

\section{Acknowledgement}

This study was supported by Shandong Key Research and Development Program-Science and Technology Innovation Project (2018CXGC0304).

\section{References}

1. A.W. Kuria, E. Barrios, T. Pagella, C.W. Muthuri, A. Mukuralinda, F.L. Sinclair, Geoderma Regional. 16, e00199 (2019)

2. H.C.J. Godfray, J.R. Beddington, I.R. Crute, L. Haddad, D. Lawrence, J.F. Muir, J. Pretty, S. Robinson, S.M. Thomas, C. Toulmin, Science. 327, 812-818 (2010)

3. J. Lehmann, S. Joseph, Biochar for environmental management: science, technology, and implementation (Routledge, New York, 2015)

4. X. Xiao, B.L. Chen, Z.M. Chen, L.Z.Zhu, J.L. Schnoor, Environ. Sci. Technol. 52, 5027-5047 (2018)

5. A. El-Naggara, S.S. Lee, J. Rinklebe, M. Farooq, H. Songe, A.K. Sarmahh, A.R. Zimmermani, M. Ahmadj, S.M. Shaheen, Y.S. Ok, Geoderma. 337, 536-554 (2019)

6. M. Ahmad, A.U. Rajapaksha, J.E. Lim, M. Zhang, N. Bolan, D. Mohan, M. Vithanage, S.S. Lee, Y.S. Ok, Chemosphere. 99, 19-33 (2014)

7. Y.H. Dai, H. Zheng, Z.X. Jiang, B.S. Xing, Sci. Total. Environ. 713, 136635 (2020)

8. Y.P. Sun, J.S Yang, R.J. Yao, X.B. Chen, X.P Wang, Sci. Rep. 10, 8946 (2020)

9. L.P. Canellas, F.L. Olivares, N.O. Aguiar, D.L. Jones, A. Nebbioso, P. Mazzei, A. Piccolo, Sci. Hortic. 196, 15-27 (2015)

10. A.S. Elrys, A.I.E. Abdo, E.M.W. Abdel-Hamed, E.M. Desoky, Ecotoxicol. Environ. Saf. 190, 110144 (2020).

11. Y.C. Zhang, X. Wang, B.J. Liu, Q. Liu, H. Zheng, X.W. You, K. Sun, X.X. Luo, F.M. Li, Chemosphere. 246, 125699 (2020)

12. H. Zheng, X. Wang, L. Chen, Z.Y. Wang, Y. Xia, Y.P. Zhang, H.F. Wang, X.X. Luo, B.S. Xing, Plant. Cell. Environ. 41, 517-532 (2018)

13. H. Bayat, F. Shafie, M.H. Aminifard, S. Daghighi, Sci. Hortic.. 279, 109912 (2021)

14. X.X. Luo, Z.Y. Wang, K. Meki, X. Wang, B.J Liu, H. Zheng, X.W. You, F.M. Li, J. Soils Sedim. 19, 39343944 (2019) 